\title{
Desarrollo de superficies modificadas oro - anticuerpo anti-PSPB para su uso como biosensor en la detección de preñez bovina
}

\author{
Keel, K. ${ }^{(1,2)}$, Tosar, J. P.(1) Laíz, J. ${ }^{(1)}$ \\ (1) Unidad de Bioquímica Analítica. Centro de Investigaciones Nucleares (CIN), Facultad de Ciencias, Universidad de la \\ República, Uruguay - (2) Departamento de Aguas y Productos Químicos. Laboratorio Tecnológico del Uruguay, LATU. \\ Contacto: jlaiz@cin.edu.uy
}

Recibido: 01/07/2010 - Aprobado: 19/10/2010

\begin{abstract}
$\underline{\text { Resumen }}$
En este trabajo se presentan los resultados preliminares para el desarrollo de un biosensor amperométrico destinado a la cuantificación de Proteína B Específica de la Preñez (PSPB) en fluidos biológicos como medio de diagnóstico clínico precoz de la preñez bovina. A la superficie de oro modificada con ácido mercaptoundecanoico (MUA) se fijaron anticuerpos anti-PSPB y peroxidasa de rábano (HRP). Se verificó la inmovilización de las biomoléculas mediante voltamperometría cíclica y medida del ángulo de contacto.Se estudió el comportamiento electroquímico del electrodo desarrollado por medio de voltamperometría cíclica y medidas a potencial constante, estableciendo la relación entre el cambio de corriente catódica (al potencial de reducción de la quinona) y la concentración de PSPB. Esta relación se ve afectada por la formación de complejos antígeno - anticuerpo que limitan el acceso del sustrato al sitio activo de la enzima, provocando una disminución en la señal eléctrica.El electrodo modificado de oro anti-PSPB - HRP respondió de forma inversamente proporcional a la concentración de PSPB a un potencial de -200 $\mathbf{m V}$ (contra electrodo de referencia $\mathrm{Ag} / \mathrm{AgCl}$ ), tanto por voltamperometría cíclica como a potencial constante, y por tanto podría ser la base para el desarrollo de un biosensor amperométrico para detectar precozmente la preñez bovina.

Palabras clave: Proteína B Específica de la Preñez, inmunosensor, voltamperometría cíclica.
\end{abstract}

\begin{abstract}
$\underline{\text { Abstract }}$
Due to big importance of early clinical diagnosis of pregnancy in cattle, the aim of this work was the development of an amperometric biosensor which enables protein quantification of pregnancy specific protein $B$ in biological fluids. To achieve this goal Mercato Undecanoic Acid was immobilized on the gold surface, with anti-PSPB and Horseradish Peroxidase. The immobilization was verified by electrochemical and non electrochemical methods, such as cyclic voltammetry and contact angle measurements respectively. The electrochemical performance of the electrode was studied by cyclic voltammetry and constant potential amperometry, to establish the relationship between the change in cathode current (the quinone reduction potential) and the concentration of PSPB. Due to the formation of large antigen antibody complexes which limit the access of the enzyme's specific substrate to its active site, the cathodic current would decrease as was observed.The developed gold - anti-PSPB - HRP electrode showed a lineal dependence on the concentration of PSPB at potential of $-200 \mathrm{mV}$ (vs Ag/AgCl), both by cyclic voltammetry and constant potential amperometry. Therefore this study could be use for the design of an amperometric biosensor which allows the detection of bovine pregnancy at the earlier stages.

Keywords: Pregnancy Specific Protein B, immunosensor, cyclic voltammetry.
\end{abstract}

\section{Introducción}

La detección temprana de la preñez en el ganado resulta relevante para el productor desde el punto de vista económico, pues permite un uso racional de los recursos disponibles. Los ensayos hormonales constituyen hasta el momento los marcadores más precoces y eficientes de la preñez bovina. Sin embargo, la valoración de Proteína B Específica de la Preñez (PSPB) ha demostrado ser un marcador mucho más eficiente que los hormonales, debido a que su concentración se incrementa a nivel sérico semanas antes de que los valores hormonales se alteren significativamente (Ropstad, 1999). Se han realizado estudios comparativos con otros métodos, los cuales demostraron que es más exacto que la valoración de progesterona (Sasser, 1986) y que el ultrasonido (Ropstad, 1999). Aproximadamente en el día 25 de la preñez los valores séricos de PSPB se acercan a $1 \mathrm{ng} / \mathrm{ml}$ (Butler, 1982). Sobre la base de los estudios efectuados en las últimas décadas, algunos investigadores han planteado que las proteínas específicas de la preñez están implicadas en el mantenimiento del cuerpo lúteo (Butler, 1982), en la regulación de la función folicular (Kiracofe, 1993), en el reconocimiento maternal de la preñez y en el mantenimiento de la misma, mediante inducción de agentes luteotróficos y mecanismos antiluteolíticos como, por ejemplo, $\mathrm{PGE}_{2}$ (Del Vecchio, 1995).

Debido a la gran importancia que reviste la detección precoz de preñez y lo útil que puede resultar la detección temprana en fluidos de la PSPB, se han desarrollado numerosos trabajos que han permitido su determinación por RIA y ELISA (enzime- linked immunosorbent assay), los métodos más empleados hasta el día de hoy (Sasser, 1986). Los inmunoensayos pueden ser específicos para PSPB, no obstante, en varios casos se dan reacciones cruzadas que impiden la unión de 
PSPB marcada con el antisuero (Semambo, 1992). A su vez, estos métodos presentan la desventaja de que deben desarrollarse en el laboratorio y por personal especialmente entrenado, lo que aumenta sus costos. Sería de interés, en consecuencia, hallar otra estrategia experimental que resultara de más fácil aplicación y/o mejorara la sensibilidad y robustez del diagnóstico. Un método novedoso podría ser el uso de biosensores electroquímicos basado en la inmovilización de anticuerpos anti-PSPB.

Las ventajas de los biosensores son su relativa simpleza, el equipamiento económico, su alta sensibilidad y su posibilidad de automatización (Ghindili,1998).

Los biosensores de afinidad, con anticuerpos como elementos de bioreconocimiento, reciben el nombre de inmunosensores (Morgan, 1996). Dado que los anticuerpos no poseen electroactividad intrínseca, se han desarrollado algunas estrategias, emplear anticuerpos o antígenos marcados con un isótopo radiactivo, enzimas, o partículas luminiscentes, entre otras, como mecanismos de detección tanto electroquímicos como no electroquímicos (Evtugyn, 2003). La inmovilización de los anticuerpos sobre la superficie del electrodo es un paso crítico, ya que deben mantener su estructura nativa para el desarrollo del biosensor (Shaojun, 1997). A tales efectos, la modificación de superficies de oro con monocapas auto-ensambladas de alcanotioles es una de las prácticas más aplicadas en los últimos años (Sun, 2005). Una monocapa de tioles auto-ensamblada se comporta como un microambiente celular con una estructura de bicapa lipídica, por lo que se pueden inmovilizar sobre ellas biomoléculas como anticuerpos, ácidos nucleicos, enzimas, etcétera (Chaki, 2002). La fijación de anticuerpos a la superficie del electrodo puede medirse por métodos no electroquímicos, como la medida del ángulo de contacto (Wang, 2006).

Entre los métodos electroquímicos de análisis, la voltamperometría cíclica es altamente utilizada en estudios de procesos de adsorción y reacciones de óxido reducción en disolución(Gileadi, 1993). Un método de detección indirecto mediante la coinmovilización de los anticuerpos y la enzima peroxidasa de rábano (HRP: Horseradish Peroxidase) ha permitido desarrollar inmunosensores amperométricos en los cuales se ha visto que la corriente catódica varía proporcionalmente con la concentración del antígeno en estudio (Evtugyn, 2003), base sobre la cual se ha llevado a cabo este trabajo.

El antígeno (PSPB) al interaccionar específicamente con los anticuerpos coinmovilizados con la enzima sobre la superficie del electrodo forma grandes complejos antígeno - anticuerpo, que limitan el acceso del sustrato específico al sitio activo de la enzima, provocando por tanto una disminución en la señal eléctrica medida (Figura 1). Por esta razón, si se comparara la señal obtenida en una disolución buffer, que contenga hidroquinona y peróxido de hidrógeno, con la obtenida, de igual forma, luego de incubar el electrodo en distintas diluciones de PSPB, se espera una inhibición de la corriente catódica proporcional al aumento de concentración de la proteína.

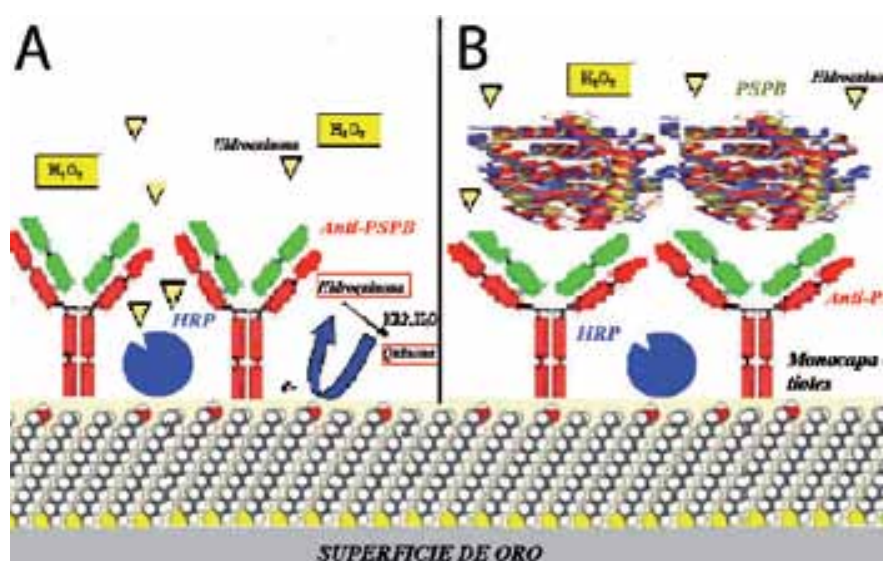

Figura 1. Esquema del funcionamiento de un inmunosensor donde se coinmoviliza anticuerpo anti-PSPB y HRP.
A. Funcionamiento del biosensor sin la presencia de PSPB, el sustrato accede hasta la enzima, la cual cataliza la reacción (Hidroquinona $\rightarrow$ Quinona) y se detecta una señal eléctrica por la reducción electroquímica de la quinona (Quinona $\rightarrow$ Hidroquinona).

B. Funcionamiento del biosensor en presencia de PSPB, la unión de la PSPB a los anticuerpos anti-PSPB limitan el acceso de la hidroquinona hasta el sitio activo de la enzima, disminuyendo la señal eléctrica producida por la reacción.

Este trabajo está orientado al desarrollo futuro de un electrodo específico para la determinación de la PSPB en fluidos biológicos. Con este objetivo se inmovilizó sobre superficies de oro anticuerpos antiPSPB y HRP. La señal se obtuvo realizando medidas electroquímicas luego de colocar el electrodo en contacto con disoluciones de PSPB de concentración creciente.

\section{Materiales y Métodos}

\section{Reactivos y soluciones}

Todos los reactivos empleados fueron de calidad puro para análisis. En la preparación de soluciones y lavado de electrodos se utilizó agua de calidad ultrapura (agua MiliQ, resistividad 18,2 $\mathrm{M} \Omega$ ). Buffer Fosfato Salino (PBS), pH 6,9, 0,0117 M ( $\mathrm{NaCl} 0,16$ $\mathrm{M}, \mathrm{KCl} 0,0027 \mathrm{M}$ ). Disolución piraña, $30 \% \mathrm{H}_{2} \mathrm{O}_{2}$ y $5 \% \mathrm{H}_{2} \mathrm{SO}_{4}(\mathrm{v} / \mathrm{v})$. $\mathrm{KMnO}_{4} 5 \%(\mathrm{~m} / \mathrm{v})$ en solución de $\mathrm{NaOH}(2,5 \mathrm{~g} / \mathrm{l})$. Disolución de Ácido Mercaptoundecanoico (MUA) $10 \mathrm{~mm}$ en etanol absoluto. La disolución de trabajo de anticuerpos anti PSPB - HRP se preparó a partir de anticuerpos liofilizados que se suspendieron en agua hasta una concentración final de $1,37 \mathrm{ug} / \mathrm{ml}$ y de una disolución de HRP 0,05 U/ml (donada por la cátedra de Bioquímica de la Facultad de Química). Para ello se adicionó un volumen de 5 ul de la disolución de HRP a una alícuota de 10 ul de la disolución de anticuerpos diluida 10 veces en buffer PBS. Como cupla indicadora en los estudios voltamétricos se utilizó $\mathrm{K}_{3}\left[\mathrm{Fe}(\mathrm{CN})_{6}\right] / \mathrm{K}_{4}\left[\mathrm{Fe}(\mathrm{CN})_{6}\right]$. $3 \mathrm{H}_{2} \mathrm{O}$ en una concentración final de $2 \mathrm{~mm}$ cada especie en una disolución de nitrato de sodio $\left(\mathrm{NaNO}_{3}\right)$ 0,2 M. Para preparar la curva de diluciones estándar de PSPB se resuspendió una muestra liofilizada de la misma en PBS hasta una concentración final de $6,3 \mu \mathrm{g} / \mathrm{ml}$; a partir de esta solución se prepararon diluciones de concentraciones finales de 500, 250, 100, 10 y $1 \mathrm{ng} / \mathrm{ml}$. Las muestras liofilizadas de PSPB y anticuerpo antiPSPB fueron donadas por el Dr. Jonathan Green, profesor asistente de la División Ciencia de los Animales de la Universidad de MissouriColumbia (http://animalscience.missouri.edu/faculty/green).

El electrodo de referencia de $\mathrm{Ag} / \mathrm{AgCl}(\mathrm{KCl} 3 \mathrm{M})$ fue preparado en el laboratorio sumergiendo un electrodo de $\mathrm{Ag} / \mathrm{AgCl}$ en una disolución de $\mathrm{KCl} 3 \mathrm{M}$ contenida en un capilar en forma de $\mathrm{U}$, estandarizándose frente a un electrodo de quinhidrona. Todo el material de vidrio utilizado fue previamente tratado con permanganato de potasio y solución piraña y luego enjuagado con abundante agua ultrapura.

\section{Limpieza de los alambres de oro}

Los alambres de oro ( $>99,99 \%$ de pureza, diámetro $1 \mathrm{~mm}$ y longitud $2 \mathrm{~cm}$, adquiridos en Goodfellow, Reino Unido) se pulieron con papel lija de grano 1000 y luego se trataron según se describe en Ruder (1988). Se verificó la limpieza mediante una voltamperometría cíclica en $\mathrm{H}_{2} \mathrm{SO}_{4} 3 \mathrm{M}$ a $100 \mathrm{mv} / \mathrm{s}$ desde 0 a $1800 \mathrm{mv}$ vs $\mathrm{Ag} / \mathrm{AgCl}(\mathrm{Fu}$, 2005). Para realizar todas las medidas por voltamperometría cíclica se utilizó un potenciostato Voltalab, Radiometer Analytical, modelo PGZ 301. Las medidas se llevaron a cabo en una celda electroquímica estándar, empleando un sistema de tres electrodos, consistente en un electrodo de trabajo de oro (u oro modificado), un contraelectrodo de carbono grafito y un electrodo de referencia de $\mathrm{Ag} / \mathrm{AgCl}$. Se midió además el ángulo de contacto de la superficie (Wang, 2006). Para ello se empleó un goniómetro, diseñado según Lages (2006). 


\section{Inmovilización de MUA y del anticuerpo anti-PSPB}

Un alambre de oro fue incubado durante 48 horas en una solución de MUA. Luego de ser enjuagado con etanol se depositó sobre su superficie la solución correspondiente de anti-PSPB y HRP, y se incubó toda una noche. Las superficies laterales del electrodo se recubrieron con teflón, dejando expuesta un área circular de $1 \mathrm{~mm}$ de diámetro correspondiente a la sección transversal del mismo. Se verificó la inmovilización mediante voltamperometría cíclica y medida del ángulo de contacto, como se describe en Mello (2002). Las medidas de voltamperometría cíclica se realizaron utilizando una velocidad de barrido de $100 \mathrm{mv} / \mathrm{s}$ y potenciales de cambio de $-200 \mathrm{y}$ $+600 \mathrm{mv}$. En las medidas de ángulo de contacto la gota depositada de agua mili Q fue de $0,1 \mu 1$.

\section{Verificación del funcionamiento del biosensor}

El comportamiento del electrodo fue estudiado mediante voltamperometría cíclica y a potencial constante, determinando en ambos casos la variación de la corriente catódica (al potencial de reducción de la quinona) en función de la concentración de PSPB. Cada electrodo se incubó en soluciones de concentración creciente de PSPB durante 15 minutos. Luego de realizadas las medias correspondientes y antes de incubar en la siguiente disolución, el electrodo se enjuagó cuidadosamente con solución buffer. En la solución de trabajo se agregó, previo a cada medida, hidroquinona y peróxido de hidrógeno hasta una concentración final de $1 \mathrm{~mm}$ de cada uno.

En la voltamperometría cíclica se utilizó siempre una velocidad de barrido de $100 \mathrm{mv} / \mathrm{s}$ y potenciales de cambio de $-500 \mathrm{y}+1000 \mathrm{mv}$. En la amperometría a potencial constante fue usada la misma celda que en casos anteriores; para su realización se diseñó un circuito formado por una fuente regulable, un milivoltímetro y un miliamperímetro. Las medidas se realizaron a $-200 \mathrm{mv}$, voltaje elegido a partir de las medidas de voltamperometría cíclica.

Todos los potenciales que se mencionan en el presente trabajo son referidos al estándar de $\mathrm{Ag} / \mathrm{AgCl}$.

\section{Resultados y Discusión}

\section{Limpieza de los alambres de oro}

Se obtuvo un voltamperograma en donde se observa la evolución de la reacción de oxígeno a partir de $+1200 \mathrm{mv}$ en la zona de oxidación anódica, mientras que en la zona de reducción catódica puede apreciarse el pico característico de la reducción del óxido formado en el barrido anódico a +900 mv. La ausencia de otros picos en la región de doble capa electroquímica del voltamperograma permite concluir que el proceso de limpieza fue efectivo y no existen otras especies redox sobre la superficie del electrodo. En consecuencia se procedió a realizar los pasos siguientes de inmovilización y detección.

\section{Verificación de inmovilización de MUA y anticuerpo}

Medidas de ángulo de contacto. El grupo carboxílico (polar) del MUA provoca un cambio de humectabilidad de la superficie (ver Figura 2 y Tabla 1), que confiere a las interfases formadas un carácter más hidrofílico y, como resultado, el ángulo de contacto disminuye (Schreiber, 2000). El valor reportado de ángulo de contacto para MUA adsorbido sobre oro es $58,1^{\circ} \pm 3,5$ (Lages, 2006), que coincide razonablemente con el valor obtenido en nuestro laboratorio, $59,4^{\circ}$ \pm 0.9 . El aumento del ángulo de contacto luego de la incubación con las proteínas (anticuerpos y HRP) indica probablemente un incremento de la hidrofobicidad de la superficie, debido a la presencia de grupos apolares de las cadenas laterales expuestas de los aminoácidos constituyentes. Los resultados obtenidos fueron reproducibles y similares a los reportados por Danczyk (2003).

\begin{tabular}{|l|c|c|c|}
\hline \multicolumn{4}{|c|}{$\begin{array}{c}\text { Ángulo contacto promedio } \\
\text { Método utilizado: Gota sésil }\end{array}$} \\
\hline & Oro & Oro - MUA & $\begin{array}{c}\text { Oro - MUA } \\
\text { Anti-PSPB y HRP }\end{array}$ \\
\hline Ángulo de contacto & 64.1 & 59,4 & 65,5 \\
\hline Desviación estándar & 1,40 & 0,86 & 0,94 \\
\hline DER (\%)* & 0,90 & 0,51 & 0,61 \\
\hline
\end{tabular}

Tabla 1. Resultados de medidas de ángulo de contacto.

*DER: Desviación Estándar Relativa. $n=5$

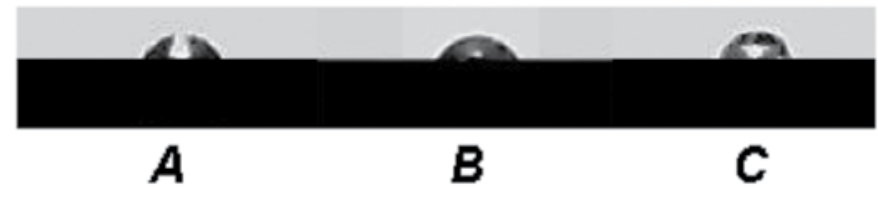

Figura 2. Imágenes de la gota de agua colocada sobre: a) oro desnudo, b) oro - MUA y c) oro - MUA - Anti-PSPB y HRP.

Voltamperometría Cíclica. En los voltamperogramas se aprecian notables cambios en dependencia del grado de modificación de la superficie (Gráfico 1). Si se formase una monocapa auto ensamblada de tioles, es de esperarse que la carga superficial negativa debida a los grupos carboxilos del MUA produzca una repulsión electrostática al caracterizar los electrodos con una cupla redox negativa $\left(\mathrm{Fe}(\mathrm{CN})_{6}^{3-}\right.$ $\left.\mathrm{Fe}(\mathrm{CN})_{6}{ }^{4}\right)$. Esto afectaría la accesibilidad de la cupla al electrodo y por consiguiente produciría una disminución de la señal. Si se comparan las curvas correspondientes al sistema oro - MUA con las registradas para el oro desnudo, se observa una importante disminución de las intensidades registradas para todos los potenciales, en particular en los potenciales de oxidación y reducción de la cupla, resultados que coinciden con los obtenidos por Chaki (2002). En conclusión, las bajas corrientes registradas permiten afirmar que se formó la monocapa de MUA.

La inmovilización de las proteínas neutraliza la carga negativa generada por la monocapa de MUA como producto de interacciones electrostáticas entre el grupo carboxílico desprotonado del ácido y el grupo amino lateral totalmente protonado de la lisina al $\mathrm{pH}$ de trabajo, reestableciéndose la capacidad de la cupla redox de acceder a la superficie. El aumento registrado en la intensidad de los picos de oxidación y reducción de la cupla evidencia que el proceso de inmovilización proteica fue exitoso.

La distancia entre los picos catódicos y anódicos aumenta en los voltamperogramas correspondientes a los electrodos oro - MUA respecto al oro desnudo, con diferencias de potencial de $200 \mathrm{mv}$ para el oro desnudo y $350 \mathrm{mv}$ para el oro incubado con MUA. Medidas similares fueron obtenidas por Wang (2004) y Chaki (2002). La distancia entre los picos para la superficie oro - MUA - anti-PSPB fue ligeramente menor que para el oro, aunque de valores aparentemente no significativos. Estos fenómenos pueden explicarse también en las diferencias de polaridades antes expuestas, la superficie negativa tiólica disminuiría la difusión, con lo cual el sistema se acercaría a condiciones de irreversibilidad. 


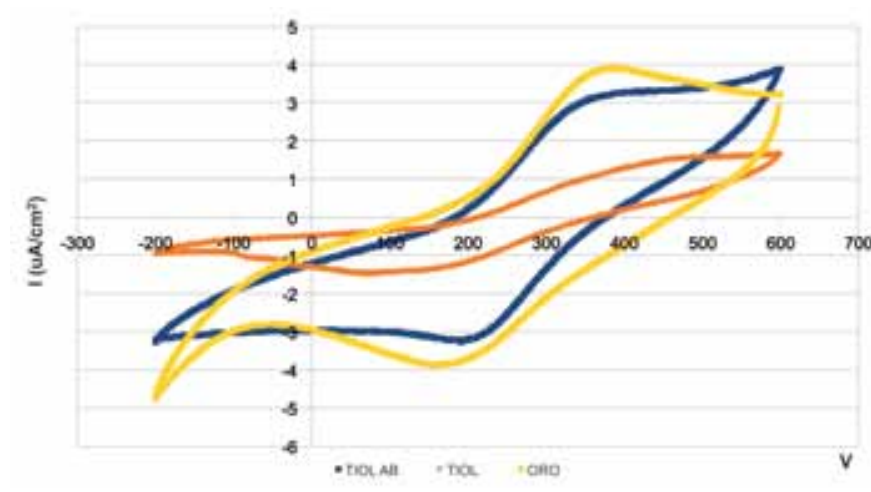

Gráfico 1. Voltamperograma cíclico de electrodo de oro desnudo (línea amarilla), incubado con MUA (línea roja) e incubado con anticuerpo anti-PSPB y HRP (línea azul).

\section{Determinación del potencial de reducción electroquímica de la quinona}

Con la finalidad de establecer el potencial de medida en el cual ocurre la reducción electroquímica de la quinona (pico catódico), se realizaron ensayos de voltamperometría cíclica (Gráfico 2). Se procuró reproducir las condiciones que serían posteriormente utilizadas para la detección de PSPB, con la diferencia de que la quinona se generó por oxidación electroquímica a $500 \mathrm{mv}$ y no enzimáticamente. Esto produjo una concentración de quinona suficientemente alta como para observar su reducción electroquímica. De este modo se estableció que en el sistema de estudio la quinona es capaz de reducirse a un potencial de $-200 \mathrm{mv}$.

\section{Verificación del funcionamiento del biosensor}

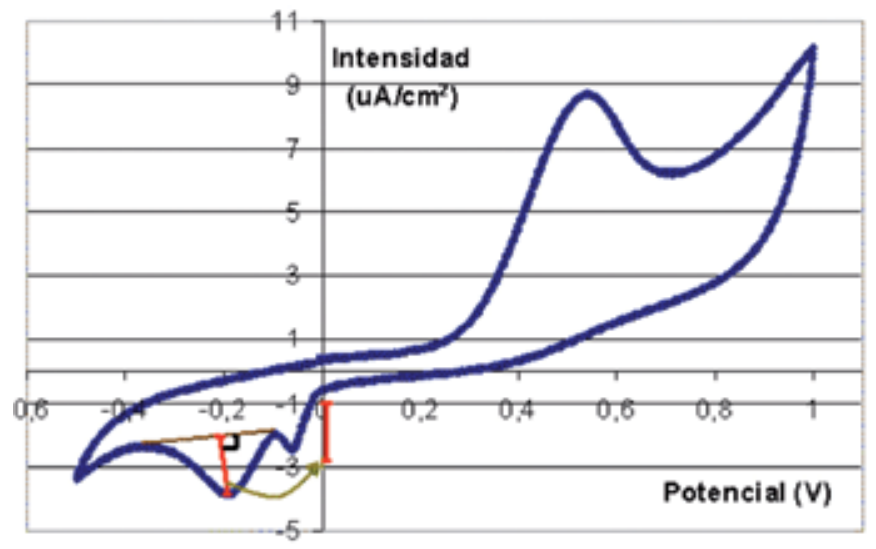

Gráfico 2. Voltamperograma de electrodo de oro - anti-PSPB - HRP sin incubación con PSPB. La medida de la intensidad del pico catódico se realizó midiendo la altura de pico con respecto a la línea de base del mismo y luego se determinó el valor de intensidad extrapolando en el gráfico. La línea de base se representa por la línea marrón y la altura de pico con la línea roja.

Voltamperometría Cíclica. Para este tipo de ensayos se incubaron los electrodos en soluciones de concentraciones crecientes de PSPB y se determinó la intensidad de corriente en el pico catódico debido a la reducción electroquímica de la quinona generada en este caso a partir de la hidroquinona por acción enzimática y electroquímica. Los resultados obtenidos se graficaron en términos de variación de la fracción de corriente en función de la concentración de PSPB (Gráfico 3). Puede apreciarse que la corriente disminuye en función del aumento de la concentración de PSPB, debido a que la unión de la proteína al anticuerpo anti-PSPB provoca un impedimento estérico que limita la unión de la hidroquinona a la enzima HRP. Como consecuencia, no se lleva a cabo la reacción enzimática, disminuyendo así la concentración de quinona disponible en solución. Una menor concentración de quinona, cuya reducción pueda ser registrada en la superficie del electrodo, provoca la disminución de la intensidad de la corriente medida.
La disminución de la corriente es proporcional al aumento de PSPB hasta ciertos niveles de concentración de proteína $(250 \mathrm{ng} / \mathrm{ml})$, a partir de los cuales se apreciaría una cierta saturación.

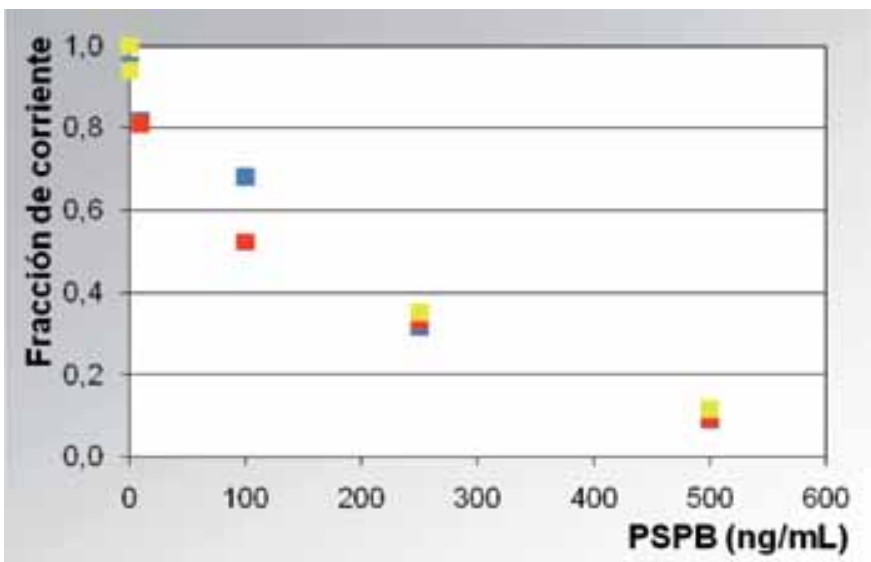

Gráfico 3. Fracción de corriente en función de la concentración de PSPB obtenido a partir de los ensayos de voltamperometría cíclica. Se muestran con diferentes colores los resultados de tres ensayos independientes.

Medidas a potencial constante. Si se comparan el gráfico de fracción de corriente en función de la concentración de PSPB obtenido a potencial constante (Gráfico 4), se observa la misma tendencia que en el gráfico obtenido por voltamperometría cíclica. Se puede observar que la saturación del electrodo a potencial constante comienza a valores menores de PSPB que para las medidas obtenidas por voltamperometría cíclica en las mismas condiciones. Por otro lado, la variación de la corriente (respuesta del electrodo) es mayor a bajas concentraciones de PSPB en las medidas a potencial constante que por voltamperometría cíclica.

Ambas observaciones indican que las medidas a potencial constante son más sensibles. El fenómeno de una mayor variación en la señal medida correspondiente a variaciones pequeñas de antígeno, en el caso de medidas a potencial constante, puede explicarse porque en ese caso la quinona proviene solamente de la acción enzimática, y se descarta de ese modo su generación electroquímica por exposición a altos potenciales, como sucede en el caso de la voltamperometría cíclica.

Además del mayor grado de respuesta, las medidas a potencial constante tienen la ventaja de que a la hora de producir el biosensor resulta más económico ya que no se requiere instrumental costoso, y su uso a nivel de campo sería más sencillo, dado que el método puede ser fácilmente automatizado.

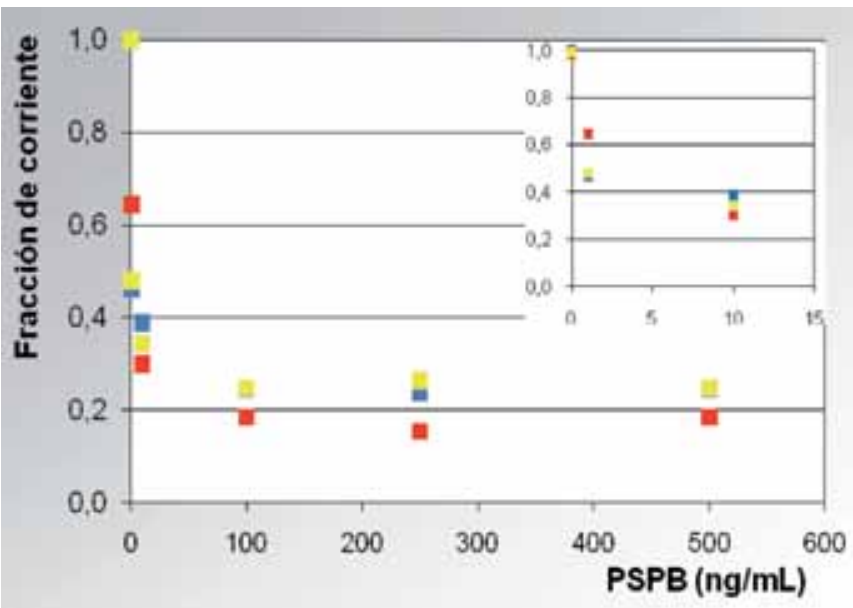

Gráfico 4. Fracción de corriente en función de la concentración de PSPB, obtenido a partir de los ensayos a potencial constante. En el recuadro se muestra en una escala más apropiada la respuesta del electrodo frente a las tres concentraciones menores. 


\section{Conclusiones}

Este trabajo constituye la base preliminar para el desarrollo de un biosensor amperométrico que permita la cuantificación de PSPB en fluidos biológicos con el fin de detectar precozmente el estado de preñez bovina.

Se ha demostrado satisfactoriamente que es posible la adsorción de anticuerpos anti-PSPB y HRP a una superficie de oro modificada previamente con un tiol por los métodos elegidos.

Las proteínas inmovilizadas sobre la superficie del electrodo conservan sus propiedades biológicas, lo que permite, por métodos electroquímicos, reconocer y cuantificar PSPB contenida en una muestra especialmente preparada.

Se ha expuesto que el uso como electrodo de la superficie modificada obtenida permite discriminar distintas concentraciones de PSPB en una muestra.

Si bien este estudio ha demostrado que la superficie desarrollada es capaz de reconocer la presencia de PSPB en muestras acuosas especialmente preparadas, es necesario realizar estudios de validación en muestras reales de sangre y sueros de animales preñados y no preñados para establecer las posibles reacciones cruzadas que pueden existir y la sensibilidad del método en una muestra real, así como el límite de detección de PSPB.

\section{Reconocimientos}

Al Dr. Santos Gama, a los integrantes de la cátedra de Bioquímica de Facultad de Química por la donación de la HRP, al Dr. Jonathan Green de la Universidad de Missouri- Columbia por la donación de anticuerpos y proteínas liofilizadas y a los integrantes del Instituto de Biomateriales de Facultad de Ciencias por permitirnos el uso de su potenciostato.

\section{Referencias}

- BUTLER, J.; HAMILTON, W.; SASSER, R.; RUDER, C.; HASS, G.; WILLIAMS, R. Detection and partial characterization of two bovine pregnancyspecific proteins. En: Biology of Reproduction. 1982, 26(5):925-933.

- CHAKI, N.; VIJAYAMOHANAN, K. Self-assembled monolayers as a tunable platform for biosensor applications. En: Biosensors and Bioelectronics. 2002, 17(1-2):1-12.

- DANCZYK, R.; KRIEDER, B.; NORTH, A.; WEBSTER, T.; HOGENESCH, H.; RUNDELL, A. Comparison of antibody functionality using different immobilization methods. En: Biotechnology and Bioengineering. 2003, 84(2):215-223.

- DEL VECCHIO, R.; SUTHERLAND, W.; SASSER, R. Effect of pregnancy-specific protein $\mathrm{B}$ on luteal cell progesterone, prostaglandin, and oxytocin production during two stages of the bovines estrous cycle. En: Journal of Animals Science. 1995, 73:2662-2668.

- EVTUGYN, G.; MINGALEVA, A.; BUDNIKOV, H.; STOIKOVA, E.; VINTER, V.; EREMIN, S. Affinity biosensors based on disposable screen-printed electrodes modified with DNA. En: Analytica Chimica Acta. 2003, 479(2):125-134.

- FU, Y.; YUAN, R.; TANG, D.; CHAI, Y. XU, L. Study on the immobilization of anti-IgG on Au-colloid modified gold electrode via. En: Colloids and Surfaces B: Biointerfaces. 2005, 40(1):6166.

- GHINDILI, A.; ATANASOV, P.; WIKINS, M. y WIKINS, E. Immunosensors: electrochemical sensing and other engineering approaches. En: Biosensors and Bioelectronics. 1998, 13:113-131.

- GILEADI, E. Electrode kinetics for chemists, chemical engineers, and material scientists. New York: VCH Publishers, 1993. ISBN: 0-471-18858-1.

- KIRACOFE, G., WRIGHT, J.; SCHALLES, R.; RUDER, C.; PARISH, S. Y SASSER R. Pregnancy-specific protein B in serum of postpartum beef cows. En: Journal of Animal Science. 1993, (71):2199-2205.

- LAGES, C. Implementación de la técnica de ángulo de contacto para el estudio de interfases. Montevideo: Facultad de Ciencias, 2006. (Tesis de grado)

- MELLO, L.; KUBOTA, L. Review of the use of biosensors as analytical tools in the food and drink industries. En: Food Chemistry. 2002, 77(2):237-256.

- MORGAN, C.; NEWMAN, D.; PRICE, C. Immunosensors: technology and opportunities in laboratory medicine. En: Clinical Chemistry. 1996, (42):193-209.

- ROPSTAD, E.; JOHANSEN, O.; KING, C.; DAHL, E.; ALBON, S.; LANGVATN, R.; IRVINE, R.; HALVORSEN, O.; SASSER,

$\mathrm{R}$. Comparison of plasma progesterone, transrectal ultrasound and pregnancy specific proteins (PSPB) used for pregnancy diagnosis in reindeer. En: Acta Vet. Scand. 1999, 40(2):151-162.

- RUDER C.; STELLFLUG, J.; DAHMEN J.; SASSER, R. Detection of pregnancy in sheep of sera for pregnancy-specific protein B. En: Theriogenology. 1988, 29(4):905-911.

- SASSER, R.; RUDER, C.; IVANI, K.; BUTLER, J. y HAMILTON W. Detection of pregnancy by radioimmunoassay of a novel pregnancy-specific protein in serum of cows and a profile of serum concentrations during gestation. En: Biology of Reproduction. 1986, 35:936-942.

- SCHREIBER, F. Structure and growth of self-assembling monolayers. En: Progress in Surfeces Science. 2000, 65(5):151256.

- SEMAMBO, D.; AYLIFFET, R.; BOYD, J.; Y TAYLOR, D. Ultrasonographic study of early embryonic loss induced by Actinomyces pyogenes in cattle. En: Veterinarian Record. 1992, 131:7-12.

- SHAOJUN, D; JINGHONG, L. Self-assembled monolayers of thiols on gold electrodes for bioelectrochemistry and biosensors. En: Bioelectrochemistry and Bioenergetics. 1997, 42(1):7-13.

- SUN, T.; FENG, L.; GAO, X.; JIANG, L. Bioinspired surfaces with special wettability. En: Acc. Chemycal. 2005, 38(8):644-352

- WANG, M.; WANG, L.; WANG, G.; JI, X.; BIE Y.; LI, T.; GONG, S. Y LI, J. Application of impedance spectroscopy for monitoring colloid Au-enhanced antibody immobilization and antibodyantigen reactions. En: Biosensors and Bioelectronics. 2004, 19(6):575-582.

- WANG Z.; VIANA, A.; JIN, G.; ABRANTES, L. Immunosensor interface based on physical and chemical immunoglobulin $\mathrm{G}$ adsorption onto mixed self-assembled monolayers. En; Bioelectrochemestry. 2006, 69(2):180-186. 